\title{
Aetiology and surgical treatment of childhood blepharoptosis
}

\author{
V Lee, H Konrad, C Bunce, C Nelson, J R O Collin
}

Br J Ophthalmol 2002;86:1282-1286

See end of article for authors' affiliations

.....................

Correspondence to: Miss Vickie Lee, FRCOphth, Oculoplastic Service, Moorfields Eye Hospital, City Road London EC1V 2PD, UK vickielee@mac.com

Accepted for publication 27 March 2002

\begin{abstract}
Aims: To describe the aetiology, demography, surgical management, and outcome of a cohort of paediatric ptosis patients in a large tertiary referral oculoplastic centre.

Methods: A case note review of all patients undergoing ptosis surgery below the age of 16 years in a tertiary referral oculoplastic unit documenting the laterality, aetiology, severity of ptosis, indications for and type of surgery undertaken, the proportion of good, suboptimal, and poor surgical outcomes, re-operations, and level of patient satisfaction.

Results: 340 patients $(82 \%$ (280/340) unilateral, 18\% (60/340) bilateral ptosis) with myogenic $(79 \%, 269 / 340)$, aponeurotic $(5 \%, 16 / 340)$, neurogenic $(11 \%, 37 / 340)$, mechanical $(2 \%, 6 / 340)$, apparent $(1 \%, 2 / 340)$, and syndrome related $(3 \%, 10 / 340)$ ptosis underwent anterior $(41 \%, 141 /$ $340)$ and posterior $(26 \%$, 90/340) levator resection, frontalis suspension with mersilene $19 \%$, $29 / 340)$ and autogenous fascia lata $(17 \%, 59 / 340)$, levator transposition $(5 \%, 15 / 340)$ and other surgery $(1 \%, 6 / 340)$ for visual $(43 \%, 141 / 333)$ and cosmetic $(57 \%, 189 / 333)$ indications. $77 \%$ $(260 / 340)$ of patients achieved a good outcome, $10 \%(35 / 340)$ a suboptimal outcome, and $13 \%$ $(45 / 340)$ a poor outcome requiring re-operation. There was no statistically significant difference in surgical outcome between patients with mild, moderate, or severe ptosis and with good, moderate, or poor levator function. The level of recorded patient satisfaction with the surgical outcome was $90 \%$ (206/229).

Conclusions: Results suggest that most groups of paediatric ptosis patients, including those with poor levator function and severe ptosis, achieve satisfactory results with the appropriate ptosis surgery.
\end{abstract}

$\mathrm{B}$ epharoptosis has a significant impact on a patient's functional status ${ }^{1}$ and may cause poor visual development in childhood. ${ }^{2}$ Although previous studies have included paediatric patients in order to demonstrate the effectiveness of a given surgical technique, there is little information in the ophthalmic literature regarding the demography and aetiology of the children with ptosis who undergo surgery and the frequency of use of these different surgical techniques. This study focuses on a paediatric ptosis cohort undergoing surgery in a tertiary referral oculoplastic centre.

\section{PATIENTS AND METHODS}

The study was a retrospective interventional case series report. The following patients were included in the study: all the patients under the age of 16 years who underwent ptosis surgery under the care of one of the authors (JROC) in the oculoplastic service at Moorfields Eye Hospital for an 8 year period between 1990 and 1997 inclusive. We recorded demographic variables including the age of the patient at surgery, their sex, the laterality of the operated eye(s), presence of amblyopia, family history of ptosis, and previous ptosis surgery. The cause and severity of the ptosis was classified according to Freuh's ${ }^{3}$ mechanistic classification and on Berke's histological findings respectively. ${ }^{4}$ In unilateral cases, the amount of ptosis was calculated as the difference in mm between the heights of the palpebral apertures: mild ptosis was defined as $2 \mathrm{~mm}$ or less lower, moderate ptosis was defined as $2-4 \mathrm{~mm}$, and severe ptosis was defined as $4 \mathrm{~mm}$ or more lower than the desired upper eyelid level; in bilateral cases the ptosis was classified as severe if the height of the palpebral fissures was less than or equal to 4 $\mathrm{mm}$, as moderate if the palpebral apertures were between 4-6 $\mathrm{mm}$, and mild if the palpebral apertures were $6 \mathrm{~mm}$ or more. Levator function was measured as the maximum lid excursion from maximal downgaze to upgaze, with frontalis function abolished. This was recorded as poor if less than $4 \mathrm{~mm}$, as moderate if between $4-8 \mathrm{~mm}$, and good if more than $8 \mathrm{~mm}$. The indications for surgery were recorded as due to visual obstruction (where the visual axis was totally or partially obscured by the ptotic upper lid without the child adopting an abnormal head posture) or cosmetic where no visual impact was expected as a result of the ptosis surgery. The type of surgery performed was recorded. Outcome was defined as good if the lids were within $1 \mathrm{~mm}$ height with an acceptable skin crease and contour with no corneal exposure and as poor if re-operation was required. A further group was identified with a suboptimal outcome-where there was more than $1 \mathrm{~mm}$ difference in lid height, and/or an asymmetric skin crease, and/or contour but who did not undergo further re-operation either because they did not want further surgery or wanted to delay until the child was mature enough to make his/her own decision and possibly to have surgery under local anaesthesia. ${ }^{5}$

\section{Types of surgery}

All the patients underwent surgery under general anaesthesia. All patients were assessed preoperatively for corneal anaesthesia and Bell's phenomenon. The choice of ptosis operation depended on the severity of the ptosis and the levator function. Levator resection was the treatment of choice in our patients with mild to moderate ptosis with levator function of more than $4 \mathrm{~mm}$. Where the ptosis was severe with moderate to poor levator function a Whitnall's sling ${ }^{6}$ or a maximal levator resection ${ }^{7}$ might be undertaken. The surgical approach could be through the intended skin crease (anterior approach) or conjunctiva $^{8}$ (posterior approach). The latter was favoured when there was a significant risk of overcorrection (in mild ptosis with good levator function) or exposure (in cases of deficient upgaze and poor Bell's phenomenon). In our experience the posterior approach offered a greater degree of control 
Table 1 Patient demography and indications for ptosis surgery

\begin{tabular}{|c|c|c|c|c|c|c|c|c|}
\hline Aetiology & $\begin{array}{l}\text { Median age } \\
\text { (range) (years) }\end{array}$ & No of males & $\begin{array}{l}\text { Bilateral } \\
\text { ptosis }\end{array}$ & $\begin{array}{l}\text { Previous } \\
\text { ptosis } \\
\text { surgery }\end{array}$ & $\begin{array}{l}\text { Family } \\
\text { history of } \\
\text { ptosis }\end{array}$ & Amblyopia & $\begin{array}{l}\text { Visual } \\
\text { indications }\end{array}$ & $\begin{array}{l}\text { Cosmetic } \\
\text { indications }\end{array}$ \\
\hline Myogenic (n=269) & $5.2(0.4-15.9)$ & $180(67 \%)$ & 52 & 59 & 46 & 67 & 114 & 149 \\
\hline Aponeurotic $(n=16)$ & $7.6(3.7-15.3)$ & $5(31 \%)$ & 1 & 1 & 3 & 1 & 5 & 10 \\
\hline Neurogenic $(n=37)$ & $6.8(1.4-15.4)$ & $17(45 \%)$ & 0 & 4 & 6 & 10 & 15 & 22 \\
\hline Mechanical $(n=6)$ & $8.5(1.3-15.6)$ & $4(67 \%)$ & 1 & 2 & 4 & 3 & 2 & 4 \\
\hline Apparent $(n=2)$ & $12.0,15.3$ & $1(50 \%)$ & 0 & 0 & 0 & 0 & 0 & 2 \\
\hline Syndrome related $(n=10)$ & $6.1(1.1-13.1)$ & $6(60 \%)$ & 6 & 0 & 4 & 4 & 8 & 2 \\
\hline $\begin{array}{l}\text { Total }(n=340) \\
(\% \text { of total) }\end{array}$ & $5.5(0.4-15.9)$ & $213(63 \%)$ & $60(18 \%)$ & $66(18 \%)$ & $64(19 \%)$ & $85(26 \%)$ & $144(43 \%)$ & $189(57 \%)$ \\
\hline
\end{tabular}

of lid height after surgery under general anaesthesia through selective timing of suture removal. ${ }^{9}$ For patients with moderate to severe ptosis with poor levator function, we favoured a frontalis suspension procedure. Our preferred suspensory material was autogenous fascia lata using the Crawford $^{10}$ method. Where fascia lata was not available, we used mersilene mesh ${ }^{11}$ utilising the Fox ${ }^{12}$ method of frontalis suspension. In cases where bilateral frontalis suspension was undertaken for unilateral ptosis, the contralateral levator was divided to promote the use of the frontalis muscle for bilateral symmetry. Levator transposition surgery was performed on patients with unilateral ptosis with aberrant movements of the levator palpebrae superioris (LPS) complex and with good voluntary levator function that preferred not to have bilateral surgery. Our two staged technique of levator transposition and resection, described in a previous publication, ${ }^{13}$ was based on the work by Lemagne et $a l^{14}{ }^{15}$ - a denervated levator transposed to the frontalis muscle in Cynomolgus monkeys would develop muscular neurotisation from the facial nerve. Stage I (levator transposition) abolished aberrant lid movements and stage II (levator resection) would be undertaken after 18 months if the lid remained low after levator neurotisation was completed. The epicanthic folds and telecanthus in blepharophimotic patients were usually corrected with a Mustardé double Z-plasty or Y-V plasty before ptosis correction was undertaken.'

\section{RESULTS}

There were 340 patients in the study with a median age of 5.5 (0.4-15.9 years). A total of $213(63 \%)$ of the patients were males and this male preponderance was found across most of the aetiological groups. The ptosis was unilateral in $280(82 \%)$ patients. Sixty six patients ( $18 \%$ ) had had previous ptosis surgery, 64 (19\%) had a family history of ptosis, and $85(26 \%)$ had an amblyopic ptotic eye. The median follow up was 8.7 (1.5-129) months; 198 patients $(58 \%)$ patients completed a 6 month follow up (Table 1).

Fifty seven per cent (189/333) of patients had cosmetic and $43 \%$ (141/333) had visual indications for ptosis surgery. The most common aetiology was myogenic $(79 \%)$ with congenital levator myopathy contributing to over $90 \%$ of this group. Eighteen patients (5\%) with blepharophimosis syndrome were also classified under the myogenic group. In the neurogenic group, patients with Marcus Gunn jaw-winking $(8 \%, 26 / 340)$ were the largest subgroup, followed by those with oculomotor palsy. Other syndromes associated with ptosis included Noonan's, ocular fibrosis, fetal alcohol, Down's, Turner's, and XXX (Table 2).

The severity of the ptosis was recorded in 337 patients. Forty four $(13 \%)$ patients had mild ptosis, 191 (57\%) had moderate ptosis, and $102(30 \%)$ had severe ptosis (Table 3$)$. The levator function was recorded in 324 patients-122 (38\%) patients had levator function of greater than $8 \mathrm{~mm}, 127$ (39\%) had moderate (4-8 mm), and $75(23 \%)$ had poor $(<4 \mathrm{~mm})$ levator function (Fig 1). Levator resection was the most common surgical procedure with 141 (41\%) via the anterior approach and $90(26 \%)$ via the posterior approach. Fifty nine (17\%) patients had brow suspension with autogenous fascia lata, and 29 (9\%) with mersilene mesh. Twenty four $(32 \%)$ patients who had levator function less than $4 \mathrm{~mm}$ underwent levator resection compared to $49(65 \%)$ who underwent brow suspension. Three of the seven patients who had superior rectus weakness underwent frontalis suspension surgery. Six of the 10 congenital third nerve palsy patients underwent frontalis suspension. Fourteen of the 27 Marcus Gunn jaw-wink (and one patient with acquired third nerve palsy) underwent the Lemagne levator transposition (13 proceeded to stage II anterior levator resection), five underwent frontalis suspension, and eight underwent levator resection (Fig 2, Tables 4 and 5).

Thirty two (9\%) patients under the age of 3 years underwent ptosis surgery for visual obstruction. The predominant aetiology was myogenic $(91 \%)$ with two patients with congenital third nerve palsy and one with mechanical ptosis secondary to neurofibromatosis. Twenty four $(75 \%)$ underwent frontalis suspension with mersilene mesh and eight $(25 \%)$ anterior levator resection. Seven patients $(22 \%)$ required further surgery. In all, $260(77 \%)$ patients (including 13 patients who required the Lemagne stage II surgery) obtained a good surgical outcome. Forty five (13\%) patients had a poor outcome and underwent re-operations and a further $35(10 \%)$ patients had a suboptimal surgical outcome

\begin{tabular}{ll}
\hline $\begin{array}{l}\text { Table } 2 \text { Composition of the cohort according to } \\
\text { ptosis aetiology }\end{array}$ & $\begin{array}{l}\text { Number of } \\
\text { patients }\end{array}$ \\
\hline Ptosis type & $269(79 \%)$ \\
\hline Myogenic & 240 \\
Simple levator maldevelopment (SLM) & 7 \\
SLM with elevator weakness (SLME) & 18 \\
Blepharophimosis & 4 \\
Other myopathy & $37(11 \%)$ \\
Neurogenic & 26 \\
Jaw-wink & 10 \\
Oculomotor nerve palsy & 1 \\
Horner's & $16(5 \%)$ \\
Aponeurotic & 12 \\
Congenital & 4 \\
Post-traumatic & $6(2 \%)$ \\
Mechanical & 4 \\
Neurofibromatosis & 2 \\
Other & $2(1 \%)$ \\
Apparent & $10(3 \%)$ \\
Syndrome related & \\
\hline &
\end{tabular}


Table 3 Severity of ptosis in different aetiological groups

\begin{tabular}{lccc}
\hline & $\begin{array}{c}\text { No of patients with } \\
\text { mild ptosis }(n=44)\end{array}$ & $\begin{array}{l}\text { No of patients with } \\
\text { moderate ptosis } \\
(n=191)\end{array}$ & $\begin{array}{l}\text { No of patients with } \\
\text { severe ptosis }(n=102)\end{array}$ \\
\hline Myogenic $(n=267)$ & 31 & 156 & 80 \\
Aponeurotic $(n=16)$ & 6 & 8 & 2 \\
Neurogenic $(n=36)$ & 5 & 18 & 13 \\
Mechanical $(n=6)$ & 0 & 3 & 3 \\
Apparent $(n=2)$ & 1 & 1 & 0 \\
Syndrome related $(n=10)$ & 1 & 5 & 4 \\
\hline
\end{tabular}

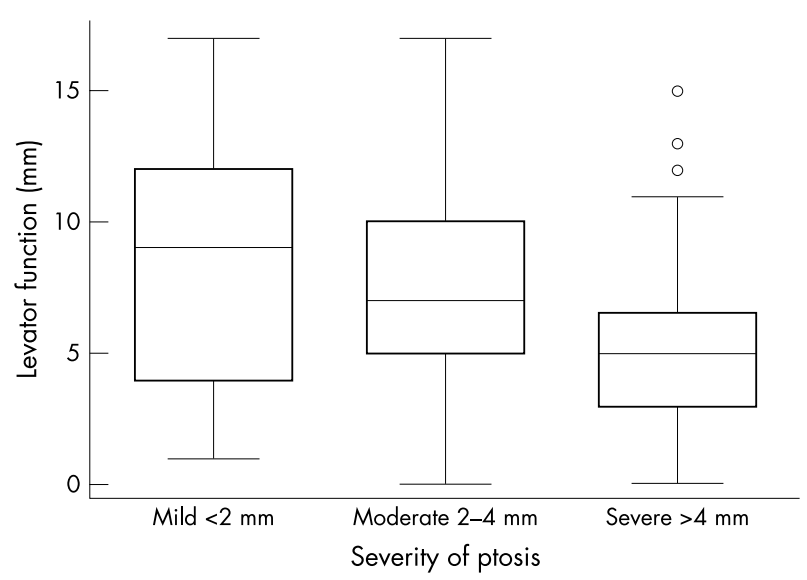

Figure 1 Box and whisker plot of severity of ptosis and levator function. This graph is a visual representation of the levator function in each category of ptosis (mild, moderate, and severe) using the median, the upper (75th, the median of the upper half of the data) and lower (25th, the median of the lower half of the data) quartiles, and the extreme values (outliers). A box is drawn around the quartile value, and the whiskers extend from each quartile to the extreme data points (the maximum and minimum observation values). The line in the middle of the box is the median level of levator function for the ptosis group - the middle of the data when it is arranged in order from least to greatest.

(Table 6). Of the patients undergoing re-operations, eight $(18 \%)$ required re-operation within the first 6 months after surgery and this was due to overcorrection with poor lid closure. The most common reason for a suboptimal or poor outcome was persistently low upper lid (Table 7). There was no statistically significant difference in the incidence of poor or suboptimal outcomes between patients who had previous surgery $(27 \%)$ and those who had not $(23 \%)$. If we limited our analysis to the largest (myogenic) group, there was no statis- tically significant difference in the incidence of poor or suboptimal surgical outcomes between those who had mild $(8 / 31$, $26 \%)$, moderate $(32 / 156,22 \%)$, or severe ptosis $(19 / 80,24 \%)$ $(\mathrm{p}=0.09)$ and those who had good $(23 / 89,26 \%)$, moderate $(24 / 108,23 \%)$, or poor $(12 / 60,20 \%)$ levator function $(p=0.7)$. The level of satisfaction of 229 patients regarding the outcome of the ptosis surgery was recorded, of which 90\% (206/229) expressed satisfaction and 10\% (23/229) expressed dissatisfaction.

\section{DISCUSSION}

To our knowledge, this is the first study to describe the aetiology, demography, surgical management, and outcome of paediatric ptosis patients in a large tertiary referral oculoplastic centre. A survey of all ptosis surgery performed in all age groups in the hospital under the care of the senior author (JROC) over the study period showed that 44\% (340/772, unpublished data) were in the paediatric age group.

\section{Incidence of paediatric ptosis}

Myogenic ptosis, especially isolated levator maldevelopment, was the most common aetiology, and formed the predominant group in patients requiring early surgery. The incidence of amblyopia (25\%) and the numbers of patients with jaw-wink ptosis $(8 \%)$ and blepharophimosis $(5 \%)$ correlated with previous large published series of congenital ptosis from other oculoplastic centres. ${ }^{21617}$ Whereas these earlier studies demonstrated the effectiveness of a specific surgical technique of ptosis correction in both adults and children, this study focused on the diverse aetiology and surgical management of this paediatric patient population.

\section{Timing and indications for paediatric ptosis surgery}

Cosmesis was the predominant indication for surgery in this paediatric cohort, although in the very young (less than 3 years) the main indication for surgery was threat to visual development. Otherwise we generally deferred blepharoptosis

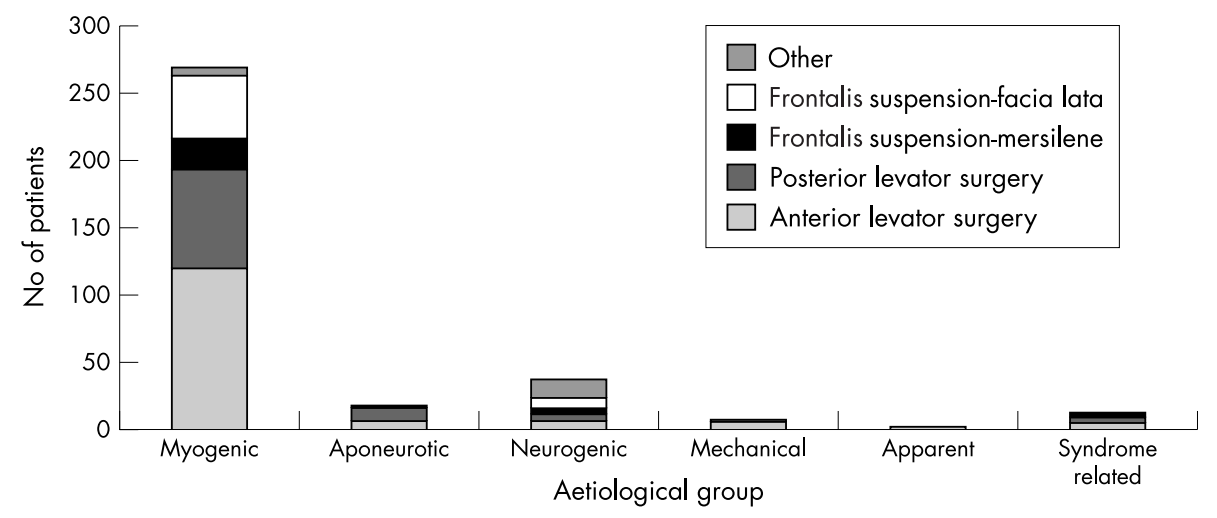

Figure 2 The distribution of the different types of surgery undertaken in each aetiological group. Bar chart showing the number of patients in each aetiological group (myogenic, aponeurotic, neurogenic, mechanical, neurogenic, and syndrome related) who have undergone each of the different types of surgery (anterior and posterior levator resection, frontalis suspension with fascia lata or mersilene, and other surgery). 
Table 4 Types of surgery in different aetiological groups

\begin{tabular}{lccccc}
\hline Aetiology & $\begin{array}{c}\text { Anterior levator } \\
\text { surgery }(n=141)\end{array}$ & $\begin{array}{l}\text { Posterior levator } \\
\text { surgery }(n=90)\end{array}$ & $\begin{array}{l}\text { Mersilene mesh } \\
\text { frontalis suspension } \\
(n=29)\end{array}$ & $\begin{array}{l}\text { Autogenous fascia } \\
\text { lata frontalis } \\
\text { suspension }(n=59)\end{array}$ & $\begin{array}{l}\text { Other } \\
(n=21)\end{array}$ \\
\hline Myogenic $(n=269)$ & 119 & 75 & 22 & 49 & 4 \\
Aponeurotic $(n=16)$ & 5 & 10 & 0 & 0 & 1 \\
Neurogenic $(n=37)$ & 6 & 5 & 4 & 7 & $15^{*}$ \\
Mechanical $(n=6)$ & 5 & 0 & 1 & 0 & 0 \\
Apparent $(n=2)$ & 1 & 0 & 0 & 3 & 0 \\
Syndrome related $(n=10)$ & 5 & 0 & 2 & & \\
\hline *Levator tranpositions. & & & & & \\
\hline
\end{tabular}

Table 5 Types of surgery undertaken in different levels of levator function

\begin{tabular}{llllr}
\hline Levator function & $\begin{array}{l}\text { Anterior levator } \\
(n=138)\end{array}$ & $\begin{array}{l}\text { Posterior levator } \\
(n=88)\end{array}$ & $\begin{array}{l}\text { MM frontalis } \\
\text { suspension }(n=21)\end{array}$ & $\begin{array}{l}\text { AFL frontalis } \\
\text { suspension }(n=58)\end{array}$ \\
\hline Good $(>8 \mathrm{~mm})(\mathrm{n}=122)$ & 35 & 70 & 0 & $\begin{array}{l}\text { Others } \\
(\mathrm{n}=19)\end{array}$ \\
Moderate $(4-8 \mathrm{~mm})(\mathrm{n}=127)$ & 80 & 17 & 7 & 3 \\
Poor $(<4 \mathrm{~mm})(\mathrm{n}=75)$ & 23 & 1 & 14 & 20 \\
\hline
\end{tabular}

Table 6 Outcomes of different types of surgery

\begin{tabular}{lccc}
\hline Surgery & $\begin{array}{c}\text { Good outcome } \\
(n=260)\end{array}$ & $\begin{array}{l}\text { Suboptimal } \\
\text { outcome }(n=35)\end{array}$ & $\begin{array}{l}\text { Poor outcome/ } \\
\text { re-operations } \\
(n=45)\end{array}$ \\
\hline Anterior levator $(n=141)$ & $97(69 \%)$ & $23(16 \%)$ & $21(15 \%)$ \\
Posterior levator $(n=90)$ & $73(81 \%)$ & $5(6 \%)$ & $12(13 \%)$ \\
Mersilene mesh frontalis suspension $(n=29)$ & $20(69 \%)$ & 0 & $9(31 \%)$ \\
Autogenous fasica frontalis suspension $(n=59)$ & $51(87 \%)$ & $5(8 \%)$ & $3(5 \%)$ \\
Other $(n=21)$ & $19(90 \%)$ & 2 & 0 \\
\hline & & & \\
\hline
\end{tabular}

Table 7 Causes of poor and suboptimal surgical outcomes

\begin{tabular}{lcl}
\hline Problem & $\begin{array}{l}\text { Suboptimal } \\
\text { outcome }(n=35)\end{array}$ & $\begin{array}{l}\text { Poor outcome/ } \\
\text { re-operation } \\
(n=45)\end{array}$ \\
\hline Lid too high & 3 & 9 \\
Lid too low & 16 & 31 \\
Skin crease problems & 5 & 2 \\
Lid contour problems & 8 & 1 \\
Other & 3 & 2 \\
\hline
\end{tabular}

surgery in children until at least the age of 3 years when levator function could be accurately measured and fascia lata harvested if necessary. In our experience many parents preferred ptosis surgery to be undertaken before the child commenced primary school at around the age of 5 years.

\section{Outcome of paediatric ptosis surgery}

The goal of blepharoptosis surgery was once described as the "elusive perfect result.." ${ }^{18}$ Predictability of lid height in adult ptosis surgery could be enhanced by using local anaesthesia ${ }^{19}$ or adjustable sutures, ${ }^{20}$ but these options were often not available when operating in a paediatric cohort. As there were no published data regarding time taken to reach final lid height stability in patients with paediatric ptosis so a follow up of 6 weeks was chosen (based on results in adult patients with aponeurotic ptosis ${ }^{21}$ ) as a stable end point. The overall incidence of poor surgical outcome of $13 \%$ in our cohort compared similarly to Beard's results (14\%) for congenital ptosis. ${ }^{16}$ Our outcomes with specific surgical techniques com- pared favourably with previous publications - the incidence of $15 \%$ poor outcome in anterior levator resection compared similarly to results published by Berke ${ }^{17}(10 \%)$ and Putterman and Ulrist $(17 \%) .{ }^{22}$ The $5 \%$ incidence of poor outcome with autogenous fascia frontalis suspension was comparable to other studies ${ }^{23}$ including Crawford's results (10\%). ${ }^{24}$ We used mersilene mesh as the non-autogenous frontalis suspensory material of choice as once the mersilene mesh was integrated, this might result in permanent ptosis correction (over two thirds of these patients did not proceed to further frontalis suspension surgery). We did not experience any problems with mersilene exposure or extrusion in this cohort. Our incidence of poor outcome with mersilene was not higher than other suspensory materials. ${ }^{25}$ The surgical outcome in groups such as those with jaw-wink ptosis also compared favourably with previous publications. ${ }^{132627}$ The Lemagne procedure should be considered as a two stage procedure: $87 \%$ of our patients (compared to $44 \%{ }^{13}$ in an earlier study from our centre) required the stage II anterior levator resection but this should not be considered a poor outcome or complication. We used both objective and subjective (patient's/family's satisfaction) measurements to describe the surgical outcome and have shown no difference in patients with varying severity of ptosis and levator function. We strongly believed that the surgeon must not fit all ptosis patients to his/her favourite operation, and we have demonstrated here that with careful patient and surgery selection in historically difficult groups of patients (with severe ptosis and poor levator function) could achieve a satisfactory result. The majority (90\%) of patients whose sentiments were recorded expressed satisfaction with the surgical outcome, although a comprehensive survey of patient satisfaction was limited by the nature of the retrospective study. In summary, appropriate ptosis surgery 
performed after careful evaluation in a paediatric patient should offer a very good prognosis, both in terms of objective and subjective improvement.

\section{Authors' affiliations}

V Lee, H Konrad, C Bunce, C Nelson, J R O Collin, Oculoplastic Service, Moorfields Eye Hospital, London, UK

The authors have no financial or proprietary interest in the material published here.

\section{REFERENCES}

1 Federeci TJ, Meyer DR, Lininger LL. Correlation of the vision related functional impairment associated with blepharoptosis and the impact of blepharoptosis surgery. Ophthalmology 1999;106:1705-12.

2 Anderson RL, Baumgarter SA. Amblyopia in ptosis. Arch Ophthalmol 1980;98:1068-9.

3 Freuh HR. The mechanistic classification of ptosis. Ophthalmology 1980;87:1019-21

4 Berke RN, Wadsworth JAC. Histology of the levator muscle in congenital and acquired ptosis. Arch Ophthamol 1955;53:413-28.

5 Collin JRO. Complications of ptosis surgery and their management. $J$ Roy Soc Med 1979;72:25-6.

6 Anderson RL, Jordan DR, Dutton JJ. Whitnall's sling for poor function ptosis. Arch Ophthalmol 1990;108: 1628-32.

7 Mauriello JA, Wagner RS, Caputo AR, et al. Treatment of congenital ptosis by maximal levator resection. Ophthalmology 1985;93:466-9.

8 Collin JRO. A ptosis repair of aponeurotic defects by the posterior approach. Br J Ophthalmol 1979;63:586-90

9 Tyers AG, Collin JRO. Colour atlas of ophthalmic plastic surgery. 1 st ed. Edinburgh: Churchill Livingstone, 1995:131-48.

10 Crawford JS. Repair of ptosis using using frontalis muscle and fascia lata. Trans Am Acad Ophthalmol Otololaryngol 1956;60:672-8.
11 Downes RN, Collin JRO. The mersilene mesh sling-a new concept in ptosis surgery. Br J Ophthalmol 1989;73:498-501

12 Fox SA. Congenital ptosis II. Frontalis sling. J Pediatr Ophthalmol 1966;3:25-8.

13 Manners RM, Rosser P, Collin JRO. Levator transposition procedure. A review of 35 cases. Eye 1996;10:539-94.

14 Lemagne JM, Brucher JM, Michiels J. Clinical biochemical and histological results of levator muscle transposition for ptosis in Cynomolgus monkeys. Orbit 1985:4:141-6.

15 Lemagne JM. Transposition of the levator muscle and its reinnervation. Eye 1988;2:189-92.

16 Beard C.The surgical treatment of blepharoptosis: a quantitative approach. Trans Am Ophthalmol Soc 1966;64:401-87.

17 Berke RN, Huckensack NJ. Results of resection of the levator muscle through a skin incision in congenital ptosis. Am Arch Ophthalmol 1959;61:177-201.

18 Carraway JH. Cosmetic and functional considerations in ptosis surgery The elusive "perfect" result. Clin Plast Surg 1988;15:185-93.

19 Linberg JV, Vasquez RJ, Chao GM. Aponeurotic ptosis repair under local anaesthesia. Ophthalmology 1988;95:1046-52.

20 Collin JRO, O'Donnell BA. Adjustable sutures in eyelid surgery for ptosis and lid retraction. Br J Ophthalmol 1994;78:167-74.

21 Tucker SM, Verhulst SJ. Stabilisation of eyelid height after aponeurosis ptosis repair. Ophthalmology 1999;106:517-22.

22 Putterman AM, Urist M.A simplified levator palpebrae superioris muscle recession to treat overcorrected blepharoptosis. Am J Ophthalmol 1974:7:358-66.

23 Wagner RS, Mauriello JA, Nelson RB, et al. Treatment of congenital ptosis with frontalis suspension. Ophthalmology 1984;91:245-8.

24 Crawford JS. Repair of ptosis using frontalis muscle and fascia lata:a 20 year review. Ophthalmic Surg 1977:8:31-40.

25 Katowitz JA. Frontalis suspension in congenital ptosis using a polyfilament cable type suture. Arch Ophthalmol 1979;97:1659-63.

26 Khwarg SI, Tarbet KJ, Dortzbach RK, et al. Management of moderate to severe Marcus Gunn jaw-winking ptosis. Ophthalmology 1999;106:1191-6. 